\title{
A importância da linfocintilografia no tratamento do carcinoma de células de Merkel
}

\author{
The role of lymphoscintigraphy in the treatment of Merkel's cells carcinoma \\ Carlos Augusto Gomes, tCBC-MG; Cléber Soares Júnior, TCBC-MG²; Ana Carolina Proença Costa ${ }^{3}$; Fernanda Freitas de \\ Brito3; Vitor Vitol Cangussú ${ }^{3}$; Camila Couto Gomes ${ }^{4}$
}

\section{RES U M O}

\begin{abstract}
O carcinoma de Células de Merkel constitui neoplasia cutânea maligna, rara e grave, de origem neuroendócrina, com comprometimento linfonodal em metade dos pacientes e metástases disseminadas em $20 \%$ quando do diagnóstico anatomopatológico. Seu tratamento não está completamente estabelecido, entretanto a pesquisa do linfonodo sentinela vem sendo considerada indispensável e pode trazer benefícios na condução terapêutica dos pacientes.
\end{abstract}

Descritores: Carcinoma de célula de Merkel. Linfonodos/cintilografia. Bióspia de linfonodo sentinela.

\section{INTRODUÇÃO}

O carcinoma de células de Merkel é neoplasia neuroendócrina de pele rara e agressiva. Descrito pela primeira vez por Toker $^{1}$ em 1972 como "carcinoma trabecular", tem o seu diagnóstico confirmado pela imunohistoquímica apresentando reatividade positiva para citoqueratina 20, enolase neuroespecífica, sinaptofisina e cromogranina e ausência de reatividade para proteína S100, antígeno comum de leucócitos, citoqueratina 7 e fator de transcrição da tireóide. Desta forma é possível diferenciá-lo principalmente de outros carcinomas e dos linfomas ${ }^{2,3}$. Sua etiologia não é clara; no entanto, a radiação ultravioleta apresenta papel significativo ${ }^{4}$.

As lesões por características são únicas, púrpurorosáceas ou acinzentadas, brilhosas, localizadas em áreas expostas ao sol (face), não dolorosas, com crescimento rápido de semanas para meses, podendo ulcerar. É mais freqüente em idosos, caucasianos e naqueles com diminuição da imunidade como nos indivíduos HIV-positivos e nos transplantados 5,6 .

O carcinoma de células de Merkel tem particularidades comuns ao melanoma cutâneo, sendo ambos oriundos da crista neural e com propensão à disseminação linfática e sanguínea. Acomete fígado, ossos, cérebro e pulmão. O prognóstico e a sobrevivência dos pacientes estão relacionados com a profundidade de invasão da lesão primária, tamanho superior a $2 \mathrm{~cm}$, gênero masculino e reci- diva regional. Tumores que invadem para além da derme têm $78 \%$ de chances de disseminarem, contra $29 \%$ naqueles restritos à derme ${ }^{7-10}$

Modalidades de tratamento da doença são referidas, entretanto nenhuma estratégia foi validada por ensaio clínico randomizado, provavelmente pela raridade da afecção (2000 casos). Entre as opções terapêuticas descritas incluem-se: extirpação da lesão primária com ampla margem, seguido de biópsia do linfonodo sentinela, dissecção linfonodal radical, radioterapia ou quimioterapia ${ }^{11}$.

Poulsen, ${ }^{12}$ demonstrou que o comprometimento metastático da cadeia linfática regional é o mais importante fator de predição quanto à disseminação da doença, por conseguinte, de sobrevivência dos pacientes. Assim, a utilização da pesquisa do linfonodo sentinela nos indivíduos portadores de carcinoma de células de Merkel pode contribuir na estratégia e planejamento terapêutico da doença e possivelmente influir no prognóstico. A evidência nos motivou a utilização do procedimento pela primeira em vez em 2002, e só agora levado à publicação.

\section{RELATO DO CASO}

Paciente feminina, leucodérmica, 58 anos, foi submetida em 2002, à biópsia excisional de lesão cutânea eritemato-papulosa, com $2 \mathrm{~cm}$ de diâmetro localizada na região glútea direita. O estudo anatomopatológico diag-

Trabalho realizado no Departamento de Cirurgia do Hospital Universitário (HU) da Universidade Federal de Juiz de Fora (UFJF)- MG-BR.

1. Professor Adjunto Doutor do Departamento de Cirurgia do Hospital Universitário (HU) da Universidade Federal de Juiz de Fora (UFJF) - MG-BR;

2. Professor Assistente Mestre do Departamento de Cirurgia do Hospital Universitário (HU) da Universidade Federal de Juiz de Fora (UFJF). - MG-

BR; 3. Acadêmicos do Departamento de Cirurgia da Faculdade de Medicina da Universidade Federal de Juiz de Fora (UFJF)- MG-BR; 4. Acadêmica do Departamento de Morfologia da Faculdade de Medicina da Universidade Federal de Juiz de Fora (UFJF)- MG-BR. 
nosticou carcinoma de Célula de Merkel, com invasão restrita à derme. (Figura 1). O exame clínico das cadeias linfáticas axilares e inguinais não mostrou linfoademegalias. 0 resultado da tomografia de tórax e da ecografia abdominal foi normal. Optou-se então pela realização da linfocintilografia e a pesquisa do linfonodo sentinela que identificou dois linfonodos na região inguinal direita, sendo ambos extirpados (Figura 2). A seguir, foi ressecada a cicatriz da biópsia excisional com $3 \mathrm{~cm}$ de margens de segurança. O estudo histopatológico com coloração por hematoxilina-eosina mostrou que ambos estavam comprometidos por metástases. Portanto, a paciente pertencia ao estágio III (T2-N1-M0) com doença locorregionale por isso foi submetida à linfadenectomia radical inguinal e ilíaca direita. O estudo da peça operatória mostrou que um linfonodo, dos 14 retirados da região inguinal, estava comprometido e que dois, dos 18 retirados da região ilíaca também estavam comprometidos por metástases. A opção seguinte, foi encaminhá-la para o serviço de oncologia clínica que indicou quimioterapia adjuvante.

\section{DESCRIÇÃO TÉCNICA}

A paciente foi internada e submetida pela manhã à linfocintilografia em câmara cintilográfica com colimador de baixa energia e alta resolução. Injetou-se pela via intradérmica $0,8 \mathrm{ml}(1,5-2 \mathrm{mCi})$ de fitato marcado com tecnécio $99 \mathrm{~m}$ nos quatro pontos cardinais da cicatriz cutânea. Após fricção local, iniciou-se a fase dinâmica do estudo com captação de imagens a cada 30 segundos durante cinco minutos. Em seguida, imagens estáticas foram obtidas e registradas em intervalo de 10 a 60 minutos. Por fim, imagem tardia com duas horas de intervalo também foi documentada.

Durante a realização do exame, registrou-se e marcou-se a pele do paciente com pontos de tinta, nos eixos anteroposterior e laterolateral. A intercessão dos pontos localizava os linfonodos sentinelas que deveriam ser extirpados. No inicio da tarde a paciente foi conduzida ao centro cirúrgico e submetida à ressecção da cicatriz operatória com $3 \mathrm{~cm}$ de margens. Prosseguiu a operação com a extirpação dos dois linfonodos sentinelas cuja incisão cutânea respeitou o sentido de possível futura linfadenectomia radical. Para este fim, contou-se com o Gama-Probe portátil, que se utilizando dos pontos demar-

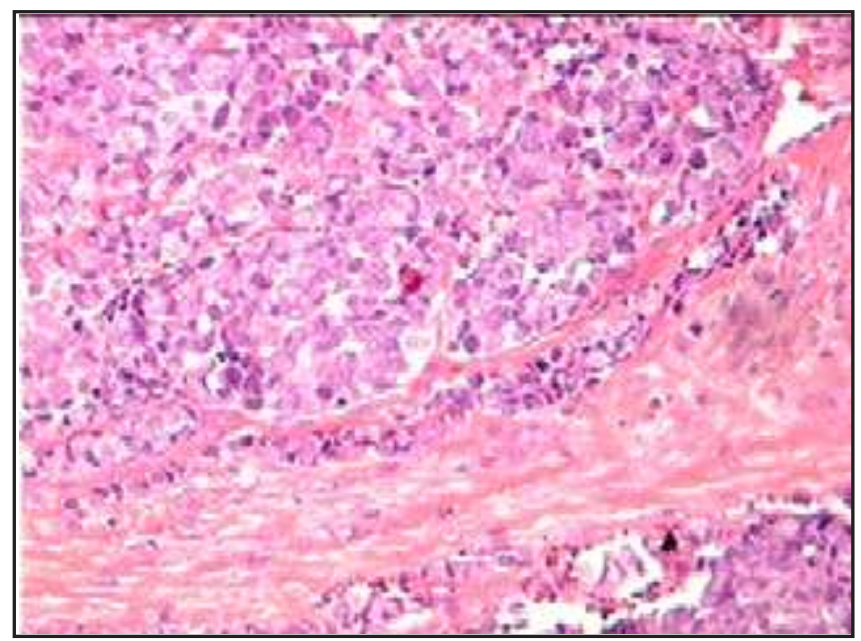

Figura 1 - Fotomicrografia de lâmina corada com hematoxilina e eosina, aumento de 100 vezes, mostrando Carcinoma de células de Merkel (neoplasia malígna de células redondas).

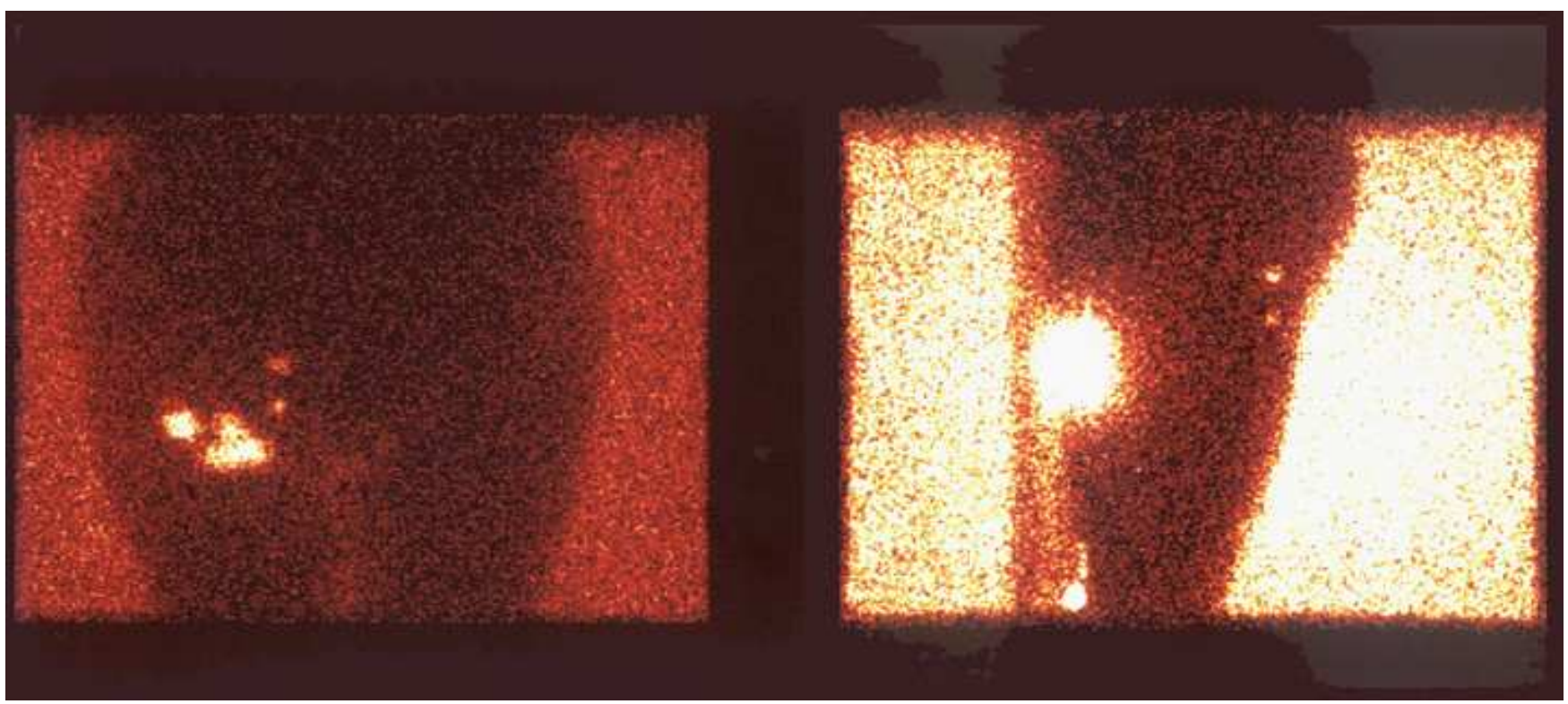

Figura 2 - Linfocintigrafia mostrando área de captação do radifármaco no local se sua injeção na cicatriz na região glútea direita e a presença de dois linfonodos sentinelas inguinais direito. 
cados, identificou os linfonodos que foram ressecados. A contagem dos linfonodos sentinelas in vivo e após sua ressecção foi aferida e registrada. A pesquisa só foi interrompida quando o número de contagens de fundo (campo operatório) se mostrou abaixo de 1/10 das contagens detectadas nos linfonodos antes de sua remoção. Por fim os espécimes cirúrgicos foram devidamente identificados e encaminhados para o laboratório de anatomia patológica e estudados com coloração da hematoxilina/eosina. Não foi necessário estudo imunohistoquímico.

O tratamento foi complementado por linfadenectomia radical inguinal e ilíaca, acompanhado de quimioterapia adjuvante. Não houve complicações na evolução pós-operatória.

\section{DISCUSSÃO}

O tratamento do carcinoma de células de Merkel não está completamente definido. As orientações terapêuticas têm por base estudos retrospectivos e relatos de casos. Entretanto, está bem estabelecido que o tratamento inicial deve ser o operatório e se fundamenta na ampla ressecção da lesão primária com 2 a $3 \mathrm{~cm}$ de margens ${ }^{13,14}$.

O carcinoma de células de Merkel apresenta comportamento biológico semelhante ao melanoma cutâneo, em sua propensão à disseminação linfática regional precoce. A recidiva regional pode ultrapassar $76 \%$ e sua presença é fator de mau prognóstico ${ }^{4}$. Assim, a pesquisa do linfonodo sentinela integrou-se ao tratamento da doença e passou a selecionar aqueles pacientes que apresentam metástases linfonodais regionais e se beneficiam da linfadenectomia radical, daqueles sem a referida disseminação ${ }^{15-17}$. Além do mais, o procedimento possibilitou definir um grupo de pacientes no qual não são necessárias outras medidas terapêuticas adjuvantes ${ }^{17}$.

O carcinoma de células de Merkel é radiossensível e o tratamento adjuvante com radioterapia tem sido recomendado ${ }^{18,19}$. Tsang et al., $2004^{20}$ avaliaram a utilização da radioterapia pós-operatória em pacientes com a doença e demonstraram que há risco de sua progressão quando a abordagem é retardada por mais de 24 dias. Portanto, recomendam que os pacientes sejam encaminhados, com prioridade, para o tratamento.

Warner et al., $2008^{21}$ do Sydney Melanoma Group verificaram que ao contrário do observado com os pacientes portadores de melanoma cutâneo, a pesquisa do linfonodo sentinela apresentou baixa acurácia quanto à predição de recidiva linfonodal da doença. Em contrapartida, o estudo enfatiza a importância da radioterapia pós-operatória no controle locorregional. Apesar de tratar-se de estudo retrospectivo, pela primeira vez os resultados são conflitantes com o estabelecido na literatura e questiona se os pacientes com lesão primária, extirpadas com margens livres e ausência ou mínimo comprometimento metastático linfonodal regional, deveriam ser sub- metidos a algum tipo de terapêutica adjuvante, notadamente o tratamento por radioterapia. Ruan e Reeves ${ }^{22}$, preocupados com a questão, idealizaram um algoritmo de tratamento do carcinoma de células de Merkel, mas especificamente neste ponto recomendam apenas "avaliar a radioterapia", deixando a decisão para juízo individual (Figura 3).

O ponto que merece destaque na nota técnica refere-se à utilização da pesquisa do linfonodo sentinela como critério que possibilitou todas as orientações terapêuticas seguintes: a linfadenectomia inguinal e ilíaca e a quimioterapia adjuvante de princípio. O fato de não se uti-

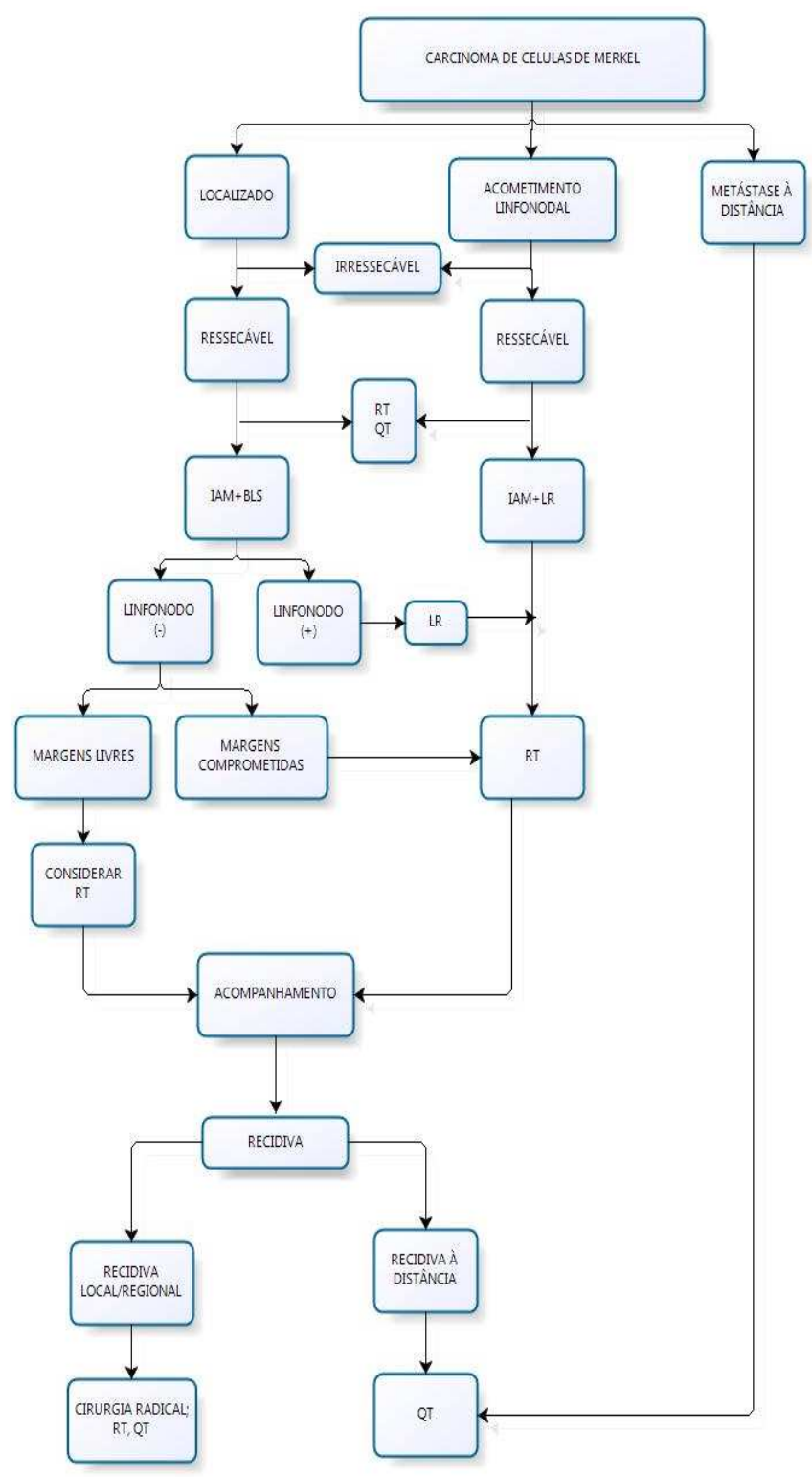

Figura 3 - $\quad$ Algoritmo de tratamento do Carcinoma de células de Merkel segundo Reevers ${ }^{22}$.

$Q T=$ Quimioterapia; $R T=$ Radioterapia; $I A M=$ Incisão com ampla margem; $B L S=$ Biópsia do linfonodo sentinela; $L R=$ linfadenectomia radical. 
lizar da radioterapia locorregional como opção terapêutica adjuvante parece, a princípio, em desacordo com a literatura que refere à redução na freqüência de recidiva da doença 19,21,23. Entretanto, deve-se ter em mente que a linfadenectomia foi radical e extirpou 35 linfonodos, identificando cinco comprometidos por micrometástases sem invasão capsular. É aconselhado nesta situação avaliar com critério a morbidez adicionada pelo tratamento radioterápico ao membro já operado. Além do mais, não está claro se a radioterapia utilizada após o adequado controle operatório locorregional da doença seja justificável. Além do mais, a recidiva regional após linfadenectomia radical com linfonodos microscopicamente comprometidos é rara ${ }^{11}$.

Por outro lado, pode-se entender a doença como sistêmica e a utilização da quimioterapia adjuvante oferecer vantagens. Warner et al., sugere o uso da quimioterapia em pacientes com comprometimento linfonodal porque, em muitos casos este é o primeiro sinal de doença disseminada ${ }^{21}$. Entretanto um estudo sobre a utilização da quimioterapia adjuvante no tratamento do carcinoma de células de Merkel, por meio de re-análise multivariada dos dados, de acordo com o estágio de apresentação da doença, contraria os resultados de pesquisa anteriormente realizada pelo mesmo grupo e não demonstra aumento na sobrevivência dos pacientes ${ }^{24}$.
O carcinoma de células de Merkel é sensível à vários agentes quimioterápicos, como doxirubicina, cisplatina, etoposide, ciclofosfamida e vincristina. Esses agentes são freqüentemente usados em associação, mas o regime com maior eficácia ainda não é conhecido. Outro fato importante é salientar que muitos pacientes com carcinoma de células de Merkel são submetidos à quimioterapia adjuvante por analogia com o tumor neuroendócrino mais comum que é o carcinoma de pulmão de células pequenas. No entanto, existem significativas diferenças entre as duas afecções que não necessariamente apontam para o fato do que seja bom para um, seja bom para o outro; e sua utilização estaria restrita aos pacientes com doença sistêmica ${ }^{23}$.

Pode-se observar que, a despeito das evidências não favorecerem à utilização da quimioterapia adjuvante no tratamento dos pacientes com carcinoma de células de Merkel, a nossa paciente respondeu favoravelmente ao tratamento proposto e encontra-se muito bem clinicamente, livre de doença, após sete anos de controle clínico e radiológico, a despeito de cinco linfonodos comprometidos microscopicamente mas, precocemente identificados com a abordagem que se discute. Pode-se especular que a radicalidade da operação realizada por médico com formação em Cirurgia Oncológica, somado ao marginal efeito da quimioterapia tenham contribuído nesta sobrevivência.

\title{
A $B$ S S T R A $A$ C T
}

\begin{abstract}
The Merkel cell carcinoma is a rare, serious, neuroendocrine, malignant skin cancer with lymph node involvement in half of patients and disseminated metastases in $20 \%$ of cases at the time of pathological diagnosis. Its treatment is not fully established, though the sentinel lymph node has been considered essential and may bring benefits to the therapeutic armamentarium of patients.
\end{abstract}

Key words: Carcinoma Merkel cell. Lymph nodes/radionuclide imaging. Sentinel lymph node biopsy.

\section{REFERÊNCIAS}

1. Toker C. Trabecular carcinoma of the skin. Arch Dermatol 1972; 105(1):107-10

2. Schmidt U, Müller U, Metz KA, Leder LD. Cytokeratin and neurofilament protein staining in Merkel cell carcinoma of the small cell type and small cell carcinoma of the lung. Am J Dermatopathol 1998; 20(4):346-51

3. Leech SN, Kolar AJ, Barrett PD, Sinclair SA, Leonard N. Merkel cell carcinoma can be distinguished from metastatic small cell carcinoma using antibodies to cytokeratin 20 and thyroid transcription factor 1. J Clin Pathol 2001; 54(9): 727-9.

4. Shaw JH, Rumball E. Merkel cell tumor: clinical behavior and treatment. Br J Surg 1991; 78(2):138-42.

5. Penn I, First MR. Merkel's cell carcinoma in organ recipients: report of 41 cases. Transplantation 1999; 68(11):1717-21.

6. An KP, Ratner D. Merkel cell carcinoma in the setting of HIV infection. J Am Acad Dermatol 2001; 45(2):309-12.

7. Boyle F, Pendlebury $S$, Bell D. Further insights into the natural history and management of primary cutaneous neuroendocrine (Merkel cell) carcinoma. Int J Radiat Oncol Biol Phys 1995; 31(2):31523
8. Poulsen M, Rischin D, Walpole E, Harvey J, Mackintosh J, Ainslie J, et al. High-risk Merkel cell carcinoma of the skin treated with synchronous carboplatin/etoposide and radiation: Trans-Tasman Radiation Oncology Group Study - TROG 96:07. J Clin Oncol 2003; 21(23):4371-6.

9. Fenig E, Brenner B, Katz A, Rakovsky E, Hana MB, Sulkes A. The role of radiation therapy and chemotherapy in the treatment of Merkel cell carcinoma. Cancer 1997; 80(5):881-5.

10. Mott RT, Smoller BR, Morgan MB. Merkel cell carcinoma: a clinicopathologic study with prognostic implications. J Cutan Pathol 2004; 31(3):217-23.

11. Brady MS. Current management of patients with merkel cell carcinoma. Dermatol Surg 2004; 30(2 Pt2):321-5.

12. Poulsen M. Merkel-cell carcinoma of the skin. Lancet Oncol 2004;5(10):593-9

13. Eng TY, Boersma MG, Fuller CD, Cavanaugh SX, Valenzuela $F$, Herman TS. Treatment of merkel cell carcinoma. Am J Clin Oncol 2004; 27(5):510-5

14. Gollard R, Weber R, Kosty MP, Greenway HT, Massullo V, Humberson C. Merkel cell carcinoma: review of 22 cases with surgical, pathologic, and therapeutic considerations. Cancer 2000; 88(8):1842-51 
15. Wasserberg N, Schachter J, Fenig E, Feinmesser M, Gutman H. Applicability of the sentinel node technique to Merkel cell carcinoma. Dermatol Surg 2000; 26(2):138-41.

16. Allen PJ, Busam K, Hill AD, Stojadinovic A, Coit DG Immunohistochemical analysis of sentinel lymph nodes from patients with Merkel cell carcinoma. Cancer 2001; 92(6):1650-5.

17. Gupta SG, Wang LC, Peñas PF, Gellenthin M, Lee SJ, Nghiem P. Sentinel lymph node biopsy for evaluation and treatment of patients with Merkel cell carcinoma: The Dana-Farber experience and meta-analysis of the literature. Arch Dermatol 2006; 142(6):68590.

18. Eich HT, Eich D, Staar S, Mauch C, Stützer H, Groth W, et al. Role of postoperative radiotherapy in the management of Merkel cell carcinoma. Am J Clin Oncol 2002; 25(1):50-6.

19. Jabbour J, Cumming R, Scolyer RA, Hruby G, Thompson JF, Lee S. Merkel cell carcinoma: assessing the effect of wide local excision, lymph node dissection, and radiotherapy on recurrence and survival in early-stage disease--results from a review of 82 consecutive cases diagnosed between 1992 and 2004. Ann Surg Oncol 2007; 14(6):1943-52.

20. Tsang G, O'Brien P, Robertson R, Hamilton C, Wratten C, Denham J. All delays before radiotherapy risk progression of Merkel cell carcinoma. Australas Radiol 2004; 48(3):371-5.

21. Warner RE, Quinn MJ, Hruby G, Scolyer RA, Uren RF, Thompson JF. Management of merkel cell carcinoma: the roles of lymphoscintigraphy, sentinel lymph node biopsy and adjuvant radiotherapy. Ann Surg Oncol 2008; 15(9):2509-18.
22. Ruan JH, Reeves M. A Merkel cell carcinoma treatment algorithm. Arch Surg 2009; 144(6):582-5.

23. Garneski KM, Nghiem P. Merkel cell carcinoma adjuvant therapy: current data support radiation but not chemotherapy. J Am Acad Dermatol 2007; 57(1):166-9.

24. Poulsen MG, Rischin D, Porter I, Walpole E, Harvey J, Hamilton C, et al. Does chemotherapy improve survival in high-risk stage I and II Merkel cell carcinoma of the skin ? Int J Radiat Oncol Biol Phys 2006; 64(1):114-9.

Recebido em 08/09/2010

Aceito para publicação em 14/11/2010

Conflito de interesse: nenhum

Fonte de financiamento: nenhuma

\section{Como citar este artigo:}

Gomes CA, Soares Júnior C, Costa ACP, Brito FF, Cangussú VV, Gomes CC. A importância da linfocintilografia no tratamento do carcinoma de células de Merkel. Rev Col Bras Cir. [periódico na Internet] 2011; 38(5). Disponível em URL: http://www.scielo.br/rcbc

\section{Endereço para correspondência:}

Carlos Augusto Gomes

E-mail: caxiaogomes@terra.com.br 